\title{
JURISPRUDENCIA AMBIENTAL EN GALICIA (SEGUNDO SEMESTRE 2019)
}

María del Carmen RodríGuez Martín-Retortillo

Profesora interina e investigadora del Área de Derecho Administrativo Universidade da Coruña 
Sumario: 1. Introducción. 2. Aspectos relacionados con el cumplimiento de las condiciones de la autorización ambiental integrada. 3. Cuestiones relativas a la denegación a la parte recurrente de su condición de interesada. 4. Declaración de interés especial de varios proyectos de producción de energía eléctrica a partir de fuentes renovables y sus infraestructuras de evacuación asociadas.

\section{INTRODUCCIÓN}

Las sentencias del Tribunal Superior de Justicia de Galicia contenidas en esta crónica se pueden estructurar en 3 grupos:

- El primero relativo a aspectos relacionados con el cumplimiento de las condiciones de la autorización ambiental integrada al hilo de la sentencia 363/2019, de 25 de junio, de la Sección Segunda de la Sala de lo ContenciosoAdministrativo del Tribunal Superior de Justicia de Galicia.

- El segundo trata cuestiones relativas a la denegación a la parte recurrente de su condición de interesada a propósito de la sentencia 349/2019, de 8 de julio, de la Sección Segunda de la Sala de lo Contencioso-Administrativo del Tribunal Superior de Justicia de Galicia.

- El tercero versa sobre la declaración de interés especial de varios proyectos de producción de energía eléctrica a partir de fuentes renovables y sus infraestructuras de evacuación asociadas analizando la sentencia 150/2019, de 5 de junio, de la Sección Tercera de la Sala de lo Contencioso-Administrativo del Tribunal Superior de Justicia de Galicia.

\section{ASPECTOS RELACIONADOS CON EL CUMPLIMIENTO DE LAS CONDICIONES DE LA AUTORIZACIÓN AMBIENTAL INTEGRADA}

La primera sentencia a tratar es la 363/2019, de 25 de junio, de la Sección Segunda de la Sala de lo Contencioso-Administrativo del Tribunal Superior de Justicia de Galicia, que resuelve el recurso interpuesto por " $X$ " contra la resolución del Secretario Xeral Técnico de Medio Ambiente, Territorio e Infraestructuras que desestima el recurso de reposición formulado por la actora contra la resolución dictada por el Secretario Xeral de Calidade e Avaliación Ambiental de la Consellería de Medio Ambiente, por delegación de la Conselleira de Medio Ambiente e Ordenación do Territorio, de 3 de diciembre de 2015 por la que se sanciona a " $X$ " con una multa por la comisión de una infracción grave tipificada en el Art. 30.3 b) de la Ley 16/2002, de 1 de julio, de prevención y 
control integrados de la contaminación y se le impone la obligación de adoptar determinadas medidas complementarias para asegurar el cumplimiento de las condiciones de la autorización ambiental integrada.

Es parte demandada la Consellería de Medio Ambiente, Territorio e Infraestruturas de La Xunta de Galicia.

El Fundamento de Derecho Primero indica que en la demanda se alega:

a) Por un lado, que "en ningún momento del procedimiento se han podido identificar los hechos infractores por los que se entienden incumplidas las condiciones de la Autorización Ambiental Integrada (AAI), lo que le ha provocado indefensión".

b) Por otro lado, en relación con el procedimiento administrativo seguido, señala que en su escrito de alegaciones solicitó la remisión de copia de las actuaciones practicadas y de la prueba topográfica practicada con ocasión de la inspección de febrero de 2015, pero esa prueba fue denegada al formar parte ya del expediente.

Este fundamento argumenta que no se ha causado indefensión a la parte demandante "porque los incumplimientos de la AAl están suficientemente caracterizados en las resoluciones recurridas y la propia recurrente hace referencia a los mismos en su demanda", añadiendo que no existe inconcreción en su descripción.

También se pronuncia acerca de que el acceso al expediente administrativo no fue impedido y concluye que no resulta acreditada la indefensión.

El Fundamento de Derecho Segundo alude a la alegación de la parte actora consistente en que hay datos contradictorios entre los recogidos en el acta de 12 de febrero de 2015 y el informe de inspección ambiental de 11 de mayo de 2015, en el que se recoge que no se hallan desviaciones de la AAI en la inspección (con base en ese informe, esgrime que el contenido de las inspecciones de la AAl no acredita ningún incumplimiento), pero dicho fundamento rechaza la existencia de contradicciones al tratarse de informes que se emiten en fechas diferentes "y que recogen la realidad de la instalación y de la actividad en los distintos momentos". 
Por tanto, concluye que los incumplimientos de la AAI en que incurrió la parte demandante "son claros y diversos, y aparecen documentados en el acta de inspección de febrero de 2015 y explicados en el informe del Servizo de Prevención e Control Integrados da Contaminación de 25/02/2015", añadiendo que "tampoco se ha desvirtuado que tales hechos comprobados por la inspección representaron un incumplimiento de las condiciones de la AAl".

Expone que "solo se han ofrecido pretextos a una situación objetiva de incumplimiento de los condicionantes de la AAl, estando suficientemente acreditado que la empresa no adaptó sus instalaciones y desarrollo productivo a las nuevas exigencias derivadas del cambio de la AAI, sin que concurra ninguna causa de fuerza mayor objetiva y acreditada que haya imposibilitado el cumplimiento de tales condicionantes, exigibles, tal y como señala el Letrado de la Xunta, durante todo el año, con independencia de la pluviosidad".

Prosigue afirmando que la diligencia exigible a la empresa incluía la realización de todo lo preciso para adaptarse a los condicionantes de la AAI, "sin que en ningún caso las circunstancias aducidas representen unos hechos imprevisibles que la recurrente no pudiera haber tenido en consideración".

El Fundamento de Derecho Tercero versa sobre la alegación de la parte actora relativa a la vulneración de la presunción de inocencia al no existir pruebas "suficientemente incriminatorias", motivo que no puede prosperar dado que este fundamento concluye que "la prueba obrante en el expediente es suficiente para justificar la concurrencia de la infracción".

El Fundamento de Derecho Cuarto se refiere a las medidas complementarias cuya adopción se requiere y a la multa impuesta.

Por lo que respecta a las primeras, la parte actora "pretende su anulación sobre la base de la doctrina de los actos propios y la buena fe, por considerar que el informe de inspección ambiental de 11 de mayo de 2015 concluyó que no se habían encontrado desviaciones de la AAI en la inspección", argumento que rechaza este fundamento, insistiendo en que no existe desproporción en las medidas requeridas y señalando que "el interés general demanda que la Administración establezca las medidas necesarias para garantizar que no se 
perpetúen desviaciones respecto a la AAI en cualquiera de sus condicionantes y que no se produzcan afecciones medioambientales".

Por lo que respecta a la multa, recoge que en la demanda se indica que "la Administración la ha fijado en el triple del importe mínimo, por apreciar reiteración o reincidencia" y esgrime motivos por los que no se puede apreciar, que no prosperan al estipular dicho fundamento que "es plenamente aplicable la agravante de reincidencia", añadiendo que "antes de la comisión de la infracción la actora ya había sido sancionada en varias ocasiones por infracciones tipificadas en la misma ley por resolución firme, al menos en la vía administrativa, siendo incluso una de ellas una sanción ya firme en la vía judicial, y el resto han sido confirmadas judicialmente tanto en primera como en segunda instancia".

En atención a lo expuesto procede la desestimación del recurso y declarar que la resolución recurrida es conforme a derecho, con imposición a la parte demandante de las costas procesales, con el límite máximo de 1500 euros por todos los conceptos.

\section{CUESTIONES RELATIVAS A LA DENEGACIÓN A LA PARTE RECURRENTE DE SU CONDICIÓN DE INTERESADA}

La segunda sentencia objeto de análisis es la 349/2019, de 8 de julio, de la Sección Segunda de la Sala de lo Contencioso-Administrativo del Tribunal Superior de Justicia de Galicia, que resuelve el recurso interpuesto en nombre y representación de "E" contra la resolución de 28 de agosto de 2017 dictada por la Confederación Hidrográfica Miño-Sil por la que se desestimó el recurso contra el Acuerdo de 19 de abril, por la que se deniega a la parte recurrente la condición de interesada en el mismo.

El Fundamento Jurídico Primero recuerda el objeto del recurso, mientras que el Segundo y el Tercero se refieren a los fundamentos de la impugnación del recurrente y de la oposición de la administración demandada, respectivamente.

El recurrente en su demanda hizo constar "la situación de pestilencia, opacidad y aspecto espumoso" del río y lo puso en conocimiento del Ayuntamiento, la Consellería de Medio Ambiente y la Confederación Hidrográfica, denegándole ésta su condición de interesado. 
Argumenta que "el T.C. en la St. 34/1994 reconoció la legitimación de una asociación ecologista por lo que con mayor motivo han de tenerla los directamente afectados, refiriendo la St. del T.S. de 6 de marzo de 2000, en relación la legitimación de una asociación de defensa del medio ambiente en relación con una sanción de caza, por lo que insiste en que el recurrente es parte interesada dada la vecindad y la titularidad de predios en la zona que al ser hereditarios dejan claro su enraizamiento, siéndole reconocida su legitimación en el seguimiento de las Diligencias Previas del Juzgado de Instrucción (...), por lo que entiende que también ha de estarlo en el procedimiento administrativo". Por ello "termina interesando la anulación de la resolución recurrida y se condene a la administración a tener por personado y parte al recurrente en el expediente, con imposición de costas a la administración".

Por su parte, la Administración demandada sostiene que "la condición de denunciante no confiere la condición de interesado en el procedimiento y el problema de la legitimación tiene un carácter casuístico y quien denuncia hechos que considera constitutivos de una infracción de aguas carece de legitimación activa para presentar alegaciones o para impugnar lo que la Confederación decida", motivo por el que "termina interesando la desestimación del recurso con imposición de costas".

El Fundamento Jurídico Cuarto señala que la codemandada comparecida "termina interesando la desestimación del recurso con imposición de costas".

El Fundamento Jurídico Sexto reproduce de forma parcial lo resuelto por el T.S. en la Sentencia de 7 de julio de 2017 (Recurso 1783/2015) donde se estudian los problemas de legitimación, la evolución jurisprudencial y lo peculiar de la acción popular que se reconoce en ella.

La sentencia del Tribunal Supremo de 16 de mayo de 2007 (recurso de casación no8001/2003), sobre la imposición de sanción por vertido no autorizado y la falta de legitimación del denunciante señalaba al respecto lo siguiente:

"El interés legítimo en que la legitimación activa consiste (artículo 19-1-a) de la L. J. 29/98) se define como cualquier ventaja que se derive para una persona del 
pronunciamiento judicial que solicita. $Y$ en el presente caso ni el demandante ha puesto de manifiesto ni este Tribunal descubre qué ventaja va a obtener aquél del hecho de que se imponga una mayor sanción a la entidad ya sancionada, como no sea la del puro interés a que la actuación de la Administración sea legal".

A continuación, añadía que "este puro interés a la legalidad no es una ventaja que afecte al reducto de sus propios intereses, y buena prueba de ello es que el ordenamiento jurídico no concede una acción pública en materia de protección del medio ambiente, ni siquiera en la (...) Ley 27/2006, de 18 de Julio, que regula los derechos de acceso a la información, de participación pública y de acceso a la justicia en materia de medio ambiente, la cual, en su artículo 22 , sólo otorga acción popular a las personas jurídicas sin ánimo de lucro y sólo cuando cumplen los requisitos de su artículo 23".

Concluye que el recurrente no ha acreditado la titularidad de un interés personal (es una persona física) que le otorgue una posición de ventaja por el hecho de que la sanción hubiera sido otra, no siendo suficiente su condición de propietario de diversos inmuebles en las inmediaciones del establecimiento donde tuvo lugar el vertido, aunque acredite su arraigo o invoque la imposibilidad de disfrutar del entorno de acuerdo con los recuerdos de su infancia, motivo por el cual se impone la íntegra desestimación del recurso al ser conforme a derecho la denegación de su legitimación a pesar de su condición de denunciante, sin imposición de costas.

\section{DECLARACIÓN DE INTERÉS ESPECIAL DE VARIOS PROYECTOS DE PRODUCCIÓN DE ENERGÍA ELÉCTRICA A PARTIR DE FUENTES RENOVABLES $Y$ SUS INFRAESTRUCTURAS DE EVACUACIÓN ASOCIADAS}

La tercera sentencia estudiada es la 150/2019, de 5 de junio, de la Sección Tercera de la Sala de lo Contencioso-Administrativo del Tribunal Superior de Justicia de Galicia, que resuelve el recurso interpuesto en nombre y representación de "E", contra la desestimación presunta por silencio administrativo del recurso de reposición interpuesto contra el acuerdo de 21 de 
diciembre de 2017 del Consello de la Xunta por el que se declaran de interés especial varios proyectos de producción de energía eléctrica a partir de fuentes renovables y sus infraestructuras de evacuación asociadas (publicado en el DOG de 6 de febrero de 2018 a través de la Resolución de 26 de diciembre de 2017 de la Dirección Xeral de Enerxía e Minas).

El Razonamiento Jurídico Primero señala que a pesar de no ampliar explícitamente el recurso a la resolución expresa, se entiende ampliado de modo implícito, al interesar en el suplico de la demanda, la nulidad del acuerdo del Consello de La Xunta del 4 de octubre de 2018, que inadmite expresamente el recurso de reposición interpuesto contra dicho acuerdo, así como la anulación de la declaración de especial interés de los proyectos de producción de energía eléctrica a partir de fuentes renovables y sus infraestructuras de evacuación asociadas.

Para sustentar su pretensión, se invocan los siguientes argumentos:

- Que no existe una situación de urgencia por motivos de interés público

- La ausencia de acreditación de concurrencia de ese interés o especial incidencia y beneficios en el ámbito industrial, social y territorial

- La vulneración del derecho de defensa de la parte demandante, por lo que suplica la estimación del recurso y la declaración de nulidad del mencionado acuerdo y la anulación de la declaración de especial interés de los proyectos de producción de energía eléctrica a partir de fuentes renovables y sus infraestructuras de evacuación asociadas sobre los cuales ostenta un interés legítimo la parte demandante, dejando sin efecto la tramitación prioritaria y urgente y con imposición de costas a la Administración demandada.

En la contestación a la demanda, la Administración adujo, a la vista de la demanda, "que el único motivo posible para la fundamentación de la impugnación del acuerdo recurrido sería la falta de motivación, alegación a la que no hace referencia de contrario la actora, pero no en lo que al fondo del asunto se refiere".

En el acuerdo recurrido se contienen los motivos por los que se declaran de interés especial varios proyectos de producción de energía eléctrica a partir de 
fuentes renovables, siendo estos motivos los que dan lugar a la reducción a la mitad de los plazos fijados. En el recurso no se alega que el acuerdo carezca de motivación, por lo tanto, se puede deducir que la recurrente la estima suficiente. También hace constar que estamos "ante un acto que no decide directa o indirectamente sobre esa cuestión de fondo ni determina la imposibilidad de continuar el procedimiento" y que esa parte alega que la reducción de plazos incide en su derecho de defensa, pero sin que ello implique "indefensión o perjuicio irreparable".

A su vez, las codemandadas, en su escrito de contestación alegan con carácter principal la inadmisibilidad del recurso por estimar que se dirige contra un acto administrativo no susceptible de recurso y de forma subsidiaria formulan su objeción a tales motivos en que la demanda de la parte actora se fundamenta.

El Razonamiento Jurídico Segundo indica que previamente a la cuestión de fondo ha de analizarse la causa de inadmisibilidad que se opone, "que ha de rechazarse por cuanto que no se considera ad procesum sino una excepción ad causam, que lógicamente tiende a la desestimación de la pretensión de fondo".

El Razonamiento Jurídico Tercero fundamenta que en este recurso hay que partir del art. 33 de la Ley 39/2015, que prevé que se podrá acordar de oficio o a petición del interesado la aplicación al procedimiento de la tramitación de urgencia, por la que se reducirán a la mitad los plazos fijados para el procedimiento ordinario, excepto los relativos a la presentación de solicitudes y recursos.

Añadiendo que no cabrá recurso contra el acuerdo que declare la aplicación de la tramitación de urgencia, sin perjuicio del procedente contra la resolución que ponga fin al procedimiento.

La resolución expresa del recurso de reposición "explica el por qué de la inadmisión que se propone y en efecto se acordó".

El Razonamiento Jurídico Cuarto alude a la Disposición Adicional Primera (Proyectos declarados de interés especial) de la Ley 8/2009, de 22 de diciembre, por la que se regula el aprovechamiento eólico en Galicia y se crean tanto el 
canon eólico como el Fondo de Compensación Ambiental, cuyo apartado 4 dispone:

"La declaración de interés especial de un proyecto tendrá como efectos la tramitación de forma prioritaria y con carácter de urgencia y la reducción a la mitad de los plazos necesarios en la instrucción del procedimiento de la autorización administrativa previa y/o de construcción, así como de los plazos en la instrucción del procedimiento de evaluación ambiental que sea necesario. Asimismo, se reducirán a la mitad los plazos necesarios en la tramitación del proyecto sectorial".

El Razonamiento Jurídico Quinto expone que en el acuerdo impugnado se contienen las razones por las que se declaran de interés especial varios proyectos de producción de energía eléctrica a partir de fuentes renovables "y que son exponentes de su motivación, cuya supuesta omisión ni siquiera denuncia la recurrente". Recuerda asimismo que la parte recurrente alega que la reducción de plazos incide directamente en su derecho de defensa, sin que ello conlleve "indefensión o perjuicio irreparable", como alega.

Continúa afirmando que si la parte recurrente considera que se le ha causado indefensión o perjuicio irreparable, como se refleja en la contestación por parte de la administración a su demanda, "lo que debería de recurrir, no es la declaración de urgencia y de reducción de trámites, como establece el acuerdo aquí impugnado, sino la resolución que puso o ha de poner fin al procedimiento o procedimientos a seguir en los que pudo o podrá alegar cuantas cuestiones de fondo que considerare o considere oportunas y percutieran o percutan en el derecho subjetivo que le ha resultado reconocido en virtud de aquella sentencia".

El Razonamiento Jurídico Sexto aclara que "como arguye la Administración, tales procedimientos parecen estar concluidos, si bien sus resoluciones fueron objeto de recurso en vía administrativa por dicha recurrente, estando ese recurso o esos recursos aún pendientes de resolución", matizando que es en esos procedimientos o en los recursos que haya interpuesto, donde deben dilucidarse todas las cuestiones sobre el fondo del asunto.

Dicho Razonamiento Jurídico concluye que decae la objeción de la supuesta "vulneración al derecho de defensa" formulada por la parte recurrente así como 
las demás objeciones que realiza contra el acuerdo recurrido, "pues los motivos que esgrime (en demanda) respecto de la "inexistencia de urgencia por motivos de interés público", respecto de la supuesta "falta de acreditación de ese interés o especial incidencia y beneficios en el ámbito industrial, social y territorial" no cohonestan con el tenor literal de las premisas normativas que dejamos transcritas", motivo por el cual se desestima el recurso sin expresa imposición de costas. 